\title{
Preliminary assessment of ecological exposure of adult residents in Fukushima Prefecture to radioactive cesium through ingestion and inhalation
}

\author{
Akio Koizumi · Kouji H. Harada - Tamon Niisoe • Ayumu Adachi • \\ Yukiko Fujii · Toshiaki Hitomi • Hatasu Kobayashi · Yasuhiko Wada • \\ Takao Watanabe $\cdot$ Hirohiko Ishikawa
}

Received: 21 October 2011/Accepted: 23 October 2011/Published online: 10 November 2011

(C) The Author(s) 2011. This article is published with open access at Springerlink.com

\begin{abstract}
Objective This study aims to estimate the ecological exposure of adult residents of Fukushima Prefecture to ${ }^{134}$ cesium (Cs) and ${ }^{137} \mathrm{Cs}$ through ingestion and inhalation between July 2 and July 8, 2011.

Methods Fifty-five sets of meals with tap water, each representing one person's daily intake, were purchased in local towns in Fukushima Prefecture. Locally produced cow's milk (21 samples) and vegetables (43 samples) were also purchased. In parallel, air sampling was conducted at 12 different sites using a high-volume sampler. Nineteen sets of control meals were collected in Kyoto in July 2011.
\end{abstract}

Electronic supplementary material The online version of this article (doi:10.1007/s12199-011-0251-9) contains supplementary material, which is available to authorized users.

A. Koizumi $(\bowtie) \cdot$ K. H. Harada · T. Niisoe · A. Adachi .

Y. Fujii - T. Hitomi · H. Kobayashi

Department of Health and Environmental Sciences,

Kyoto University Graduate School of Medicine,

Kyoto 606-8501, Japan

e-mail: koizumi.akio.5v@kyoto-u.ac.jp

Y. Wada

Department of Lifestyle Design, Faculty of Human

Life and Environmental Science, University of Kochi,

Kochi 780-8515, Japan

T. Watanabe

Tohoku Bunkyo College, Yamagata 990-2361, Japan

H. Ishikawa ( $\square)$

Severe Storm and Atmospheric Environment Section, Research Division of Atmospheric and Hydrospheric Disaster

Division, Disaster Prevention Research Institute,

Kyoto University, Uji 611-0011, Japan

e-mail: ishikawa@storm.dpri.kyoto-u.ac.jp
${ }^{134} \mathrm{Cs}$ and ${ }^{137} \mathrm{Cs}$ levels in the samples were measured using a germanium detector.

Results Radioactivity was detected in 36 of the 55 sample meals from Fukushima, compared with one of 19 controls from Kyoto. The median estimated dose level ( $\mu \mathrm{Sv} /$ year) was 3.0, ranging from not detectable to 83.1. None of the cow's milk (21) or vegetable (49) samples showed levels of contamination above the current recommended limits (Bq/ $\mathrm{kg}$ ) of 200 for milk and 500 for vegetables. The total effective dose levels by inhalation were estimated to be $<3 \mu \mathrm{Sv} / \mathrm{year}$ at nine locations, but samples at three other locations close to the edge of the $20-\mathrm{km}$ radius from the crippled nuclear power plant showed higher levels of contamination ( $\mu \mathrm{Sv} / \mathrm{year}): 14.7$ at Iitate, 76.9 at Namie, and 27.7 at Katsurao.

Conclusions Levels of exposure to ${ }^{134} \mathrm{Cs}$ and ${ }^{137} \mathrm{Cs}$ in Fukushima by ingestion and inhalation are discernible, but generally within recommended limits.

Keywords ${ }^{134} \mathrm{Cs} \cdot{ }^{137} \mathrm{Cs}$ - Exposure assessment . Fukushima Daiichi nuclear power plant accident . Ingestion · Inhalation

\section{Introduction}

Following the Tohoku earthquake and tsunami on March 11, 2011, the Fukushima Daiichi nuclear power plant exploded on March 15, 2011, releasing massive amounts of radionuclides, including iodine, cesium (Cs), strontium, and plutonium into the northern part of Japan and the Pacific Ocean, being the second largest nuclear accident, after the Chernobyl disaster [1,2]. The total amount of ${ }^{137} \mathrm{Cs}$ released into the environment by the Fukushima Daiichi nuclear plant from March 11 to April 15 
$\left(1.3 \times 10^{16} \mathrm{~Bq}\right)$ [3] has been estimated to be $10 \%$ of that emitted by the Chernobyl disaster in 1986 [1, 2].

Residents living within a $20-\mathrm{km}$ radius of the nuclear power plant were evacuated soon after the disaster, but people in Fukushima Prefecture have continued to live outside this evacuation zone. Although the direct threat from the radioactive plume is over, it is important to continuously assess the exposure doses due to deposited radioactivity. Contamination with ${ }^{137} \mathrm{Cs}$ has been reported in residential areas in Fukushima Prefecture [4], and the internal doses resulting from inhalation of resuspended deposits [5] and ingestion of contaminated foods need to be monitored.

Residents in particular, but also people in remote areas, are seriously concerned about their levels of internal exposure to radionuclides through ingestion of contaminated food and drink. The ingested dose should be evaluated on the basis of the level of radioactivity contained in complete meals consumed (Bq/day/person), rather than on the radioactive content of an individual item $(\mathrm{Bq} / \mathrm{kg})$.

To evaluate potential post-accident internal doses, we conducted a field survey in July 2011, focusing on estimated exposures of adult residents of Fukushima Prefecture to ${ }^{134} \mathrm{Cs}$ and ${ }^{137} \mathrm{Cs}$ through ingestion and inhalation.

\section{Materials and methods}

Field survey

We tested whole-day meals, vegetables from local food venders, tap water, and air samples from cities at various distances from the nuclear power plant between July 2 and July 8, 2011 (Fig. 1). In the cities denoted as "M" and "V" in Fig. 1, we purchased whole-day meals and vegetables from local food venders, respectively. Tap water was also collected in the same towns or cities. In the cities denoted by "A," we conducted air sampling using a high-volume sampler (HV-1000F; Sibata, Saitama, Japan) and soil sampling (mixed soil samples from depth of $0-5 \mathrm{~cm}$ ). We also collected continuous air samples at a fixed point in Fukushima City using a low-volume sampler (SL-30; Sibata, Saitama, Japan) with an eight-stage Andersen cascade impactor sampler (AN-200; Tokyo Dylec Co., Tokyo, Japan).

Food collection and processing for radioactivity determinations

Five male researchers (aged 32-68 years) visited one of the most popular local grocery stores in each city or town and purchased several sets of whole-day meals, according to their personal preferences, as reported previously [6]. A set of whole-day meals comprised prepackaged breakfast, lunch, and dinner, as well as desserts, snacks, and

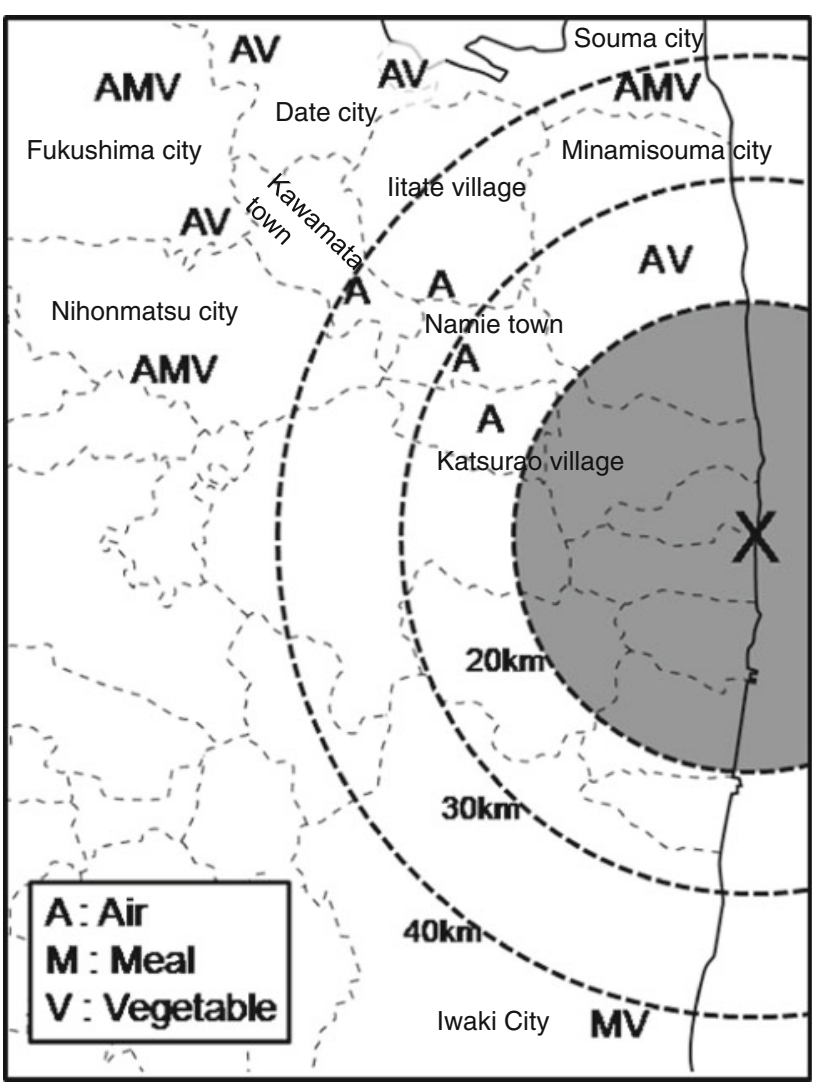

Fig. 1 Geographical locations of the field study areas. "A" represents sites where air sampling was conducted. " $\mathrm{M}$ " represents grocery stores where meals were purchased. Tap water $(12 \mathrm{~L})$ was collected in the same towns where meals were purchased. "V" represents commercial vender where vegetables were purchased. " $\mathrm{X}$ " represents the Fukushima Daiichi nuclear power plant. The symbols approximately represent actual geographical positions

beverages. A total of $12 \mathrm{~L}$ geographically matched tap water per town was donated by residents of the towns where the grocery stores were located. Locally produced vegetables and cow's milk were also purchased in the same towns. All items were transported daily to Kyoto University at $4^{\circ} \mathrm{C}$ for processing and analysis.

Daily whole-day meal sets were homogenized with locally collected tap water (approximately $1 \mathrm{~L}$ ), together with desserts and snacks. The final volumes were recorded, and approximately $1 \mathrm{~L}$ of each homogenate was processed for freeze-drying. Vegetables and cow's milk were also freeze-dried. Control meals consisted of whole-day meals collected by 19 females using the food duplicate method, as previously reported [6]. Control meals were collected in July 2011 in Uji, Kyoto, which is located from $540 \mathrm{~km}$ to the southwest of the Fukushima nuclear power plant.

Air sampling and determination of radioactivities

A high-volume air sampler was used to collect dust in the air on a quartz membrane filter. A minimum of $50 \mathrm{~m}^{3}$ was 
inspired at all sampling sites at a height of $1.5 \mathrm{~m}$ above ground. An Andersen low-volume sampler was used to collect dust of various aerodynamic diameters to estimate the respirable portion of dust in Fukushima Prefecture. This sampler was fixed at a sampling site in Fukushima City. Dust samples were weighed, and their radioactivities were measured.

Determination of ${ }^{137} \mathrm{Cs}$ and ${ }^{134} \mathrm{Cs}$

Aliquots of 100-200 $\mathrm{g}$ from each sample of food and cow's milk (dry weight), and soil (fresh weight) were weighed and sealed in cylindrical plastic containers. Filters from aerosol sampling were pressed into small cylindrical plastic containers. Radiometric determinations were performed using a high-purity, low-background, high-resolution germanium detector $(0.7 \mathrm{keV})$. The detector was protected by a lead shield, $10 \mathrm{~cm}$ thick internally, covered with $0.5 \mathrm{~mm}$ electrolytic copper. A multichannel analyzer (4,096 channels, range 0-3,000 keV, MCA8000; Princeton Gamma Technologies, NJ, USA) was used for gamma-spectrum acquisition and processing. Characteristic gamma-ray energies were monitored to identify and quantify the radionuclides $\left({ }^{134} \mathrm{Cs} 604.7\right.$ and $\left.795.9 \mathrm{keV},{ }^{137} \mathrm{Cs} 661.7 \mathrm{keV}\right)$. The detector was calibrated using a gamma-ray reference source from the Japan Radioisotope Association (Tokyo, Japan). The gamma spectrum of each sample was measured for
$>20,000 \mathrm{~s}$ for food and dust samples and for $>2,000 \mathrm{~s}$ for soil samples. The lower limits of detection were $0.05 \mathrm{~Bq} /$ $\mathrm{kg}, 0.2 \mathrm{~Bq} / \mathrm{kg}, 0.2 \mathrm{~Bq} / \mathrm{kg}, 0.2 \mathrm{mBq} / \mathrm{m}^{3}$, and $1 \mathrm{~Bq} / \mathrm{kg}$ for food, vegetable, milk, dust, and soil samples, respectively. All samples were assumed to be in radioactive equilibrium. All activities were corrected to March 15, 2011 using physical half-lives $\left({ }^{134} \mathrm{Cs} 2.06\right.$ years, ${ }^{137} \mathrm{Cs} 30.1$ years $)$.

Effective dose coefficients for exposures by ingestion and inhalation

Radioactivities were converted into effective doses using effective dose coefficients of $0.019 \mu \mathrm{Sv} / \mathrm{Bq}$ for ${ }^{134} \mathrm{Cs}$ and $0.013 \mu \mathrm{Sv} / \mathrm{Bq}$ for ${ }^{137} \mathrm{Cs}$ by ingestion, respectively [7]. For inhalation, we assumed that a standard adult resident inhaled $20 \mathrm{~m}^{3}$ air per day and used the effective dose coefficients of $0.02 \mu \mathrm{Sv} / \mathrm{Bq}$ for ${ }^{134} \mathrm{Cs}$ and $0.039 \mu \mathrm{Sv} / \mathrm{Bq}$ for ${ }^{137} \mathrm{Cs}$ for inhalation [7]. For the two routes of exposure, we postulated conservatively that all the radionuclides were retained in the body or in the lung, with no elimination.

\section{Results and discussion}

A total of 74 sets of whole-day meals were collected and analyzed. Their menus and components are presented in

Table 1 Dietary intake of radioactive cesium in Fukushima Prefecture

\begin{tabular}{|c|c|c|c|c|c|c|c|}
\hline \multirow[t]{2}{*}{ Sampling site } & \multirow[t]{2}{*}{$n$} & & \multirow[t]{2}{*}{ Food volume (g/day) } & \multirow[t]{2}{*}{ Water content $(\%)$} & \multicolumn{2}{|c|}{ Daily intake (Bq/day) } & \multirow{2}{*}{$\begin{array}{l}\text { Estimated dose } \\
(\mu \text { Sv/year })\end{array}$} \\
\hline & & & & & ${ }^{134} \mathrm{Cs}$ & ${ }^{137} \mathrm{Cs}$ & \\
\hline \multirow[t]{3}{*}{ Fukushima total } & 55 & $n>\operatorname{MDL}(\%)$ & - & - & $36(65.5)$ & $35(63.6)$ & \\
\hline & & Median (range) & $2,053(1,100-3,145)$ & 80.8 (73.3-97.6) & $0.2(\mathrm{ND}-7.2)$ & $0.3(\mathrm{ND}-7.0)$ & $3.0(\mathrm{ND}-83.1)$ \\
\hline & & Mean \pm SD & $2,178 \pm 400$ & $81.9 \pm 4.5$ & $0.5 \pm 1.1$ & $0.6 \pm 1.0$ & $6.4 \pm 12.5$ \\
\hline \multirow[t]{3}{*}{ Iwaki } & 10 & $n>\operatorname{MDL}(\%)$ & - & - & $9(90.0)$ & $9(90.0)$ & \\
\hline & & Median (range) & $2,241(1,879-2,690)$ & $82.1(76.8-86.1)$ & $0.4(\mathrm{ND}-2.5)$ & 0.7 (ND-1.6) & 6.5 (ND-24.7) \\
\hline & & Mean \pm SD & $2,238 \pm 272$ & $81.5 \pm 3.3$ & $0.7 \pm 0.8$ & $0.7 \pm 0.5$ & $8.6 \pm 7.8$ \\
\hline \multirow[t]{3}{*}{ Souma } & 10 & $n>\operatorname{MDL}(\%)$ & - & - & $7(70.0)$ & $8(80.0)$ & \\
\hline & & Median (range) & $2,451(2,044-2,795)$ & $80.5(73.3-87.1)$ & $0.6(\mathrm{ND}-7.2)$ & 0.9 (ND-7.0) & $8.2(\mathrm{ND}-83.1)$ \\
\hline & & Mean \pm SD & $2,395 \pm 293$ & $80.1 \pm 4.2$ & $1.4 \pm 2.2$ & $1.6 \pm 2.2$ & $17.4 \pm 25.3$ \\
\hline \multirow[t]{3}{*}{ Nihonmatsu } & 10 & $n>\operatorname{MDL}(\%)$ & - & - & $5(50.0)$ & $4(40.0)$ & \\
\hline & & Median (range) & $2,611(1,964-3,145)$ & $79.4(75.1-82.6)$ & $0.1(\mathrm{ND}-0.9)$ & ND (ND-0.9) & 1.7 (ND-10.4) \\
\hline & & Mean \pm SD & $2,529 \pm 423$ & $78.9 \pm 2.3$ & $0.3 \pm 0.4$ & $0.2 \pm 0.3$ & $2.9 \pm 3.6$ \\
\hline \multirow[t]{3}{*}{ Fukushima } & 25 & $n>\operatorname{MDL}(\%)$ & - & - & $15(60.0)$ & $14(56.0)$ & \\
\hline & & Median (range) & $1,954(1,100-3,051)$ & 83.7 (77.9-97.6) & $0.1(\mathrm{ND}-0.8)$ & 0.2 (ND-1.3) & $1.3(\mathrm{ND}-11.3)$ \\
\hline & & Mean \pm SD & $1,927 \pm 308$ & $84.1 \pm 4.8$ & $0.2 \pm 0.2$ & $0.2 \pm 0.3$ & $2.6 \pm 3.1$ \\
\hline \multirow[t]{3}{*}{ Kyoto (Uji) } & 19 & $n>\operatorname{MDL}(\%)$ & - & - & $1(5.3)$ & $1(5.3)$ & - \\
\hline & & Maximum & - & - & 0.4 & 0.5 & 5.3 \\
\hline & & Mean $\pm \mathrm{SD}$ & $2,955 \pm 652$ & $87.2 \pm 2.5$ & - & - & - \\
\hline
\end{tabular}

Estimated dose is the total for doses attributable to exposure to ${ }^{134} \mathrm{Cs}$ and ${ }^{137} \mathrm{Cs}$. The effective dose coefficients for ${ }^{134} \mathrm{Cs}$ and ${ }^{137} \mathrm{Cs}$ by oral route were 0.019 and $0.013 \mu \mathrm{Sv} / \mathrm{Bq}$, respectively

$M D L$ method detection limit, $N D$ less than MDL 
Table 2 Radioactive cesium in local commercial products purchased in Fukushima Prefecture

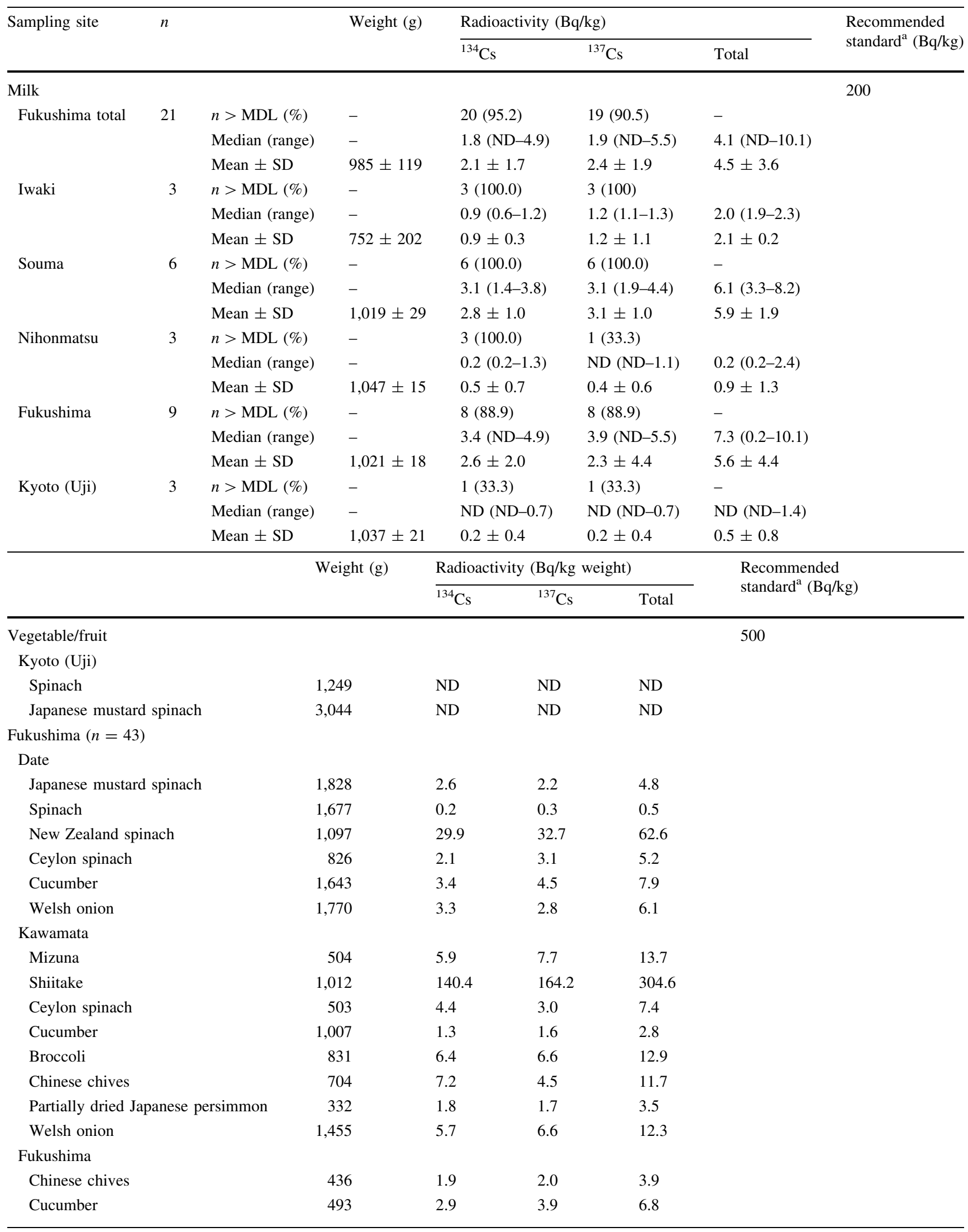


Table 2 continued

\begin{tabular}{|c|c|c|c|c|c|}
\hline & \multirow[t]{2}{*}{ Weight (g) } & \multicolumn{3}{|c|}{ Radioactivity (Bq/kg weight) } & \multirow{2}{*}{$\begin{array}{l}\text { Recommended } \\
\operatorname{standard}^{\mathrm{a}}(\mathrm{Bq} / \mathrm{kg})\end{array}$} \\
\hline & & $\overline{{ }^{134} \mathrm{Cs}}$ & ${ }^{137} \mathrm{Cs}$ & Total & \\
\hline \multicolumn{6}{|l|}{ Iwaki } \\
\hline Spinach & 1,903 & 0.5 & 0.9 & 1.4 & \\
\hline Snap bean & 860 & 3.5 & 3.6 & 7.1 & \\
\hline Shiitake & 89 & ND & ND & ND & \\
\hline Green onion & 571 & 7.3 & 8.5 & 15.8 & \\
\hline Chinese chives & 615 & 2.8 & 3.5 & 6.3 & \\
\hline Broccoli & 1,479 & 0.9 & 1.1 & 2.0 & \\
\hline Ceylon spinach & 1,079 & 1.5 & 2.6 & 4.0 & \\
\hline Garlic & 691 & 0.8 & 0.5 & 1.3 & \\
\hline \multicolumn{6}{|l|}{ Souma } \\
\hline Welsh onion & 1,543 & 4.1 & 2.6 & 6.7 & \\
\hline Peach & 794 & 9.3 & 7.9 & 17.2 & \\
\hline Cherry & 244 & 29.3 & 37.3 & 66.6 & \\
\hline Broad beans & 418 & 4.9 & 6.0 & 10.9 & \\
\hline Onion (large) & 835 & 0.5 & 0.6 & 1.1 & \\
\hline Onion (small) & 430 & 9.1 & 9.2 & 18.3 & \\
\hline Red onion (large) & 589 & 3.3 & 5.0 & 8.3 & \\
\hline Red onion (small) & 524 & 9.6 & 11.6 & 21.3 & \\
\hline Garlic & 256 & 9.4 & 7.2 & 16.6 & \\
\hline Potato & 1,258 & 1.0 & 0.8 & 1.8 & \\
\hline \multicolumn{6}{|l|}{ Minamisouma } \\
\hline Carrot & 1,271 & 1.4 & 2.1 & 3.5 & \\
\hline Shiitake & 417 & 127.1 & 154.7 & 281.8 & \\
\hline Bell pepper & 502 & ND & ND & ND & \\
\hline \multicolumn{6}{|l|}{ Nihonmatsu } \\
\hline Asparagus & 637 & 1.3 & 1.5 & 2.8 & \\
\hline Bell pepper & 390 & 12.0 & 10.7 & 22.7 & \\
\hline Ceylon spinach & 1,533 & 1.7 & 3.2 & 4.9 & \\
\hline Cucumber & 2,064 & 3.6 & 4.3 & 7.9 & \\
\hline Welsh onion & 1,309 & 5.4 & 5.0 & 10.5 & \\
\hline Cherry & 352 & 24.5 & 28.5 & 52.9 & \\
\hline
\end{tabular}

$M D L$ method detection limit, $N D$ less than MDL

${ }^{\text {a }}$ Recommended by Ministry of Health, Labor, and Welfare of Japan [8]

Table S1. Radioactivity per daily intake (Bq/day) is also summarized in Table $1 .{ }^{134} \mathrm{Cs}$ or ${ }^{137} \mathrm{Cs}$ was detected in 36 of 55 whole-day meal samples from Fukushima Prefecture, compared with only one of 19 from Kyoto. The estimated median dose levels was $3.0 \mu \mathrm{Sv} /$ year, ranging from not detectable (ND) to $83.1 \mu \mathrm{Sv} /$ year in Fukushima, while the maximum dose level in Kyoto was $5.3 \mu \mathrm{Sv} /$ year.

The levels of ${ }^{134} \mathrm{Cs}$ and ${ }^{137} \mathrm{Cs}$ in cow's milk and vegetables were also determined (Table 2). The median total activity in milk from Fukushima Prefecture was $4.1 \mathrm{~Bq} / \mathrm{kg}$, ranging from ND to 10.1 , which was an order of magnitude lower than the recommended limit set by the Ministry of Health, Labor, and Welfare of Japan [8]. Trace radioactivity was detected in only one sample from Kyoto. No vegetables in Fukushima Prefecture exceeded 100 Bq/ $\mathrm{kg}$, except for shiitake mushrooms (Lentinula edodes), which contained relatively high levels of radioactivity, up to $60 \%$ of the recommended limit (Table 2). Radioactivities in shiitake at Kawamata or Minamisouma were larger than at Iwaki, indicating that a radioactive plume was transferred by northeasterly winds from the nuclear plant. No radioactivity was detected in vegetables from Kyoto. These results indicate that the levels of radioactive $\mathrm{Cs}$ ingested were well below the recommended limits [8] in various towns in Fukushima Prefecture, except in the case of shiitake. 


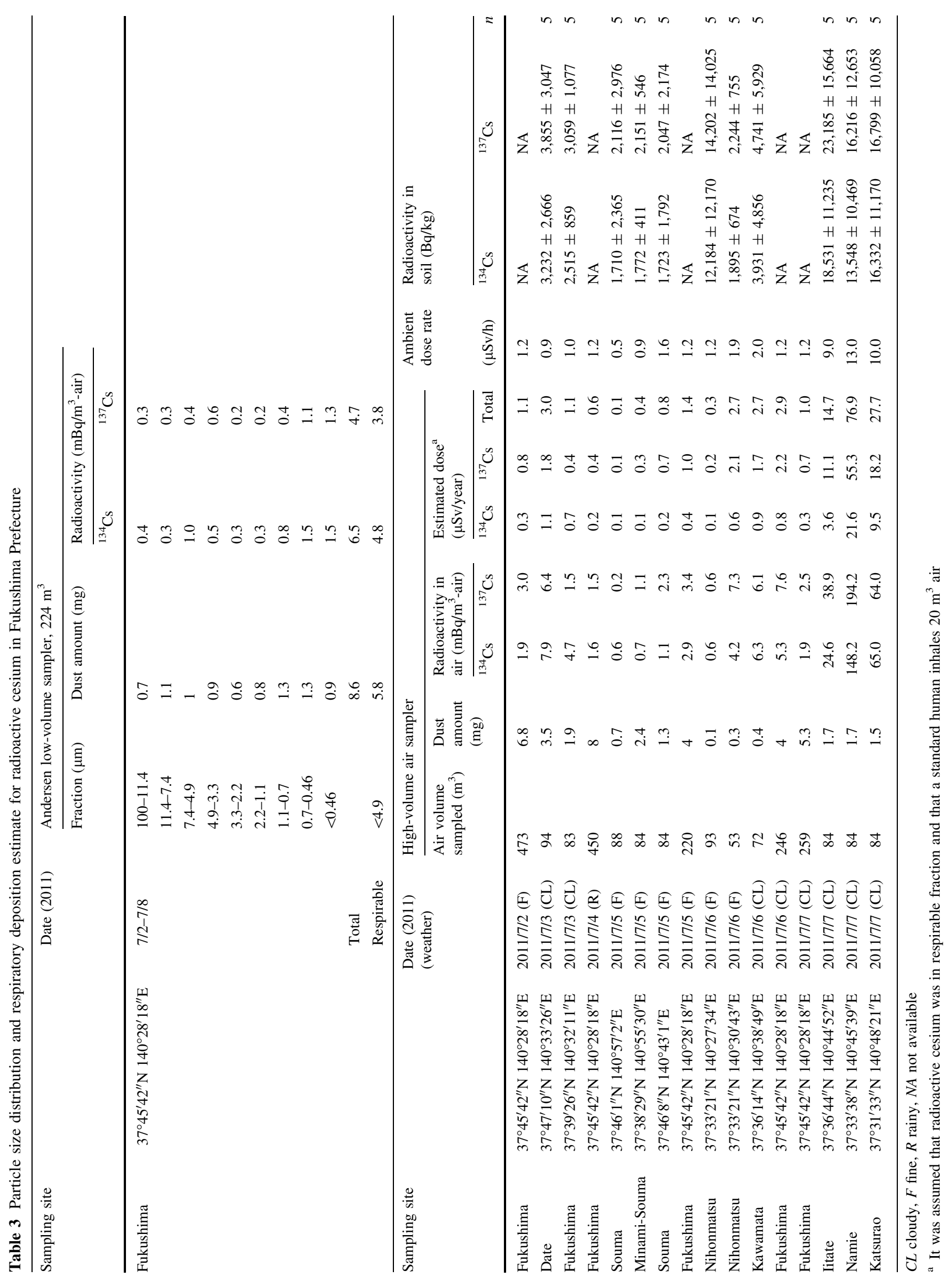


We collected 16 dust samples using the high-volume sampler (Table 3; Fig. 1). Data obtained with the low-flowvolume sampler suggested that a large proportion of the radionuclides from the crippled Fukushima nuclear power plant was in the respirable fraction: $74 \%(4.8 / 6.5)$ of the total ${ }^{134} \mathrm{Cs}$ and $81 \%(3.8 / 4.7)$ of the total ${ }^{137} \mathrm{Cs}$ (Table 3). To estimate the exposure doses for humans, we therefore selected a conservative scenario whereby all ${ }^{134} \mathrm{Cs}$ and ${ }^{137} \mathrm{Cs}$ activities in the dust samples collected using the high-volume sampler were allocated to the respirable fraction (aerodynamic diameter $<4.9 \mu \mathrm{m}$ ). The highest dose level of $76.9 \mu \mathrm{Sv} / \mathrm{year}$ was recorded in a sample collected at Namie. However, this value was still less than one-tenth of the permissible dose level of $1 \mathrm{mSv} /$ year [8]. The estimated dose levels for ${ }^{137} \mathrm{Cs}$ were significantly correlated with ambient dose rate $(\mu \mathrm{Sv} / \mathrm{h})(n=10$, $\left.r^{2}=0.79, p<0.05\right)$ but not with mean radioactivity levels in soil $(\mathrm{Bq} / \mathrm{kg})\left(n=11, r^{2}=0.32, p>0.05\right)$.

Given that the samples in this study were obtained in early July, about 4 months after the major release of radioactivity, airborne radioactivity was likely to represent resuspended deposited radioactivity, rather than direct transport from the source. Several studies have investigated resuspension from a flat surface [5], but information on resuspension from ecological systems including forests and paddy fields is scant.

We demonstrated the radioactivity levels due to ${ }^{134} \mathrm{Cs}$ and ${ }^{137} \mathrm{Cs}$ in Fukushima Prefecture in July 2011. The maximum total exposure dose through inhalation and ingestion was estimated to be $160 \mu \mathrm{Sv} / \mathrm{year}$ ( 83.1 by ingestion and 76.9 by inhalation) in zones outside a $20-\mathrm{km}$ radius of the crippled Fukushima nuclear power plant.

The amounts of radioactivity in the daily meals consumed by residents of the study regions were well below the regulation limit. However, many food items are now imported globally, such that a high portion of foodstuffs comes from uncontaminated areas. It is possible that the radioactivity in some highly contaminated foodstuffs may be diluted by other "clean" foods. However, the ingested doses estimated in the present study would underestimate the exposure of residents whose daily foods are mostly supplied locally from within the contaminated areas. The conclusions of this study may therefore not be applicable to people in such a situation. Furthermore, the current study only utilized air monitoring in a few, geographically limited areas. All meal samples were obtained from outside a $30-\mathrm{km}$ radius of the nuclear power plant, because no commercial venders were present between 20 and $30 \mathrm{~km}$ from the power plant, which had been defined as the planned emergency evacuation zone. In addition to the small number of air samples collected, the survey was conducted in the rainy season when "resuspension" is relatively low. The current study is thus subject to the above limitations and biases. However, the conservative approach adopted in this study maximized the estimated dose levels and would thus partially mitigate the effects of any biases and limitations. In conclusion, the estimated dose levels in residents of Fukushima Prefecture as a result of ingestion and inhalation were much lower than the $1 \mathrm{mSv} /$ year, recognized as a publicly permissible dose [8]. Further studies are needed to perform qualitative risk assessments based on more accurate exposure estimates.

Acknowledgments This study was supported by a Grant-in-Aid for Health Sciences Research from the Ministry of Health, Labor, and Welfare of Japan (H21-Food-003), an urgent collaborative research grant from the Disaster Prevention Research Institute, Kyoto University (23U-01), and Tokyo Kenbikyoin Foundation.

Conflicts of interest The authors declare that there are no conflicts of interest.

Open Access This article is distributed under the terms of the Creative Commons Attribution Noncommercial License which permits any noncommercial use, distribution, and reproduction in any medium, provided the original author(s) and source are credited.

\section{References}

1. Fukushima radioactive fallout nears Chernobyl levels. Newscientist.com. 2011. http://www.newscientist.com/article/dn20285-fuku shima-radioactive-fallout-nears-chernobyl-levels.html. Accessed 24 Apr 2011.

2. Peter Grier. Was Chernobyl really worse than Fukushima? The Christian Science Monitor. 2011. http://www.csmonitor.com/USA/ 2011/0426/Was-Chernobyl-really-worse-than-Fukushima. Accessed 26 Apr 2011.

3. Chino M, Nakayama H, Nagai H, Terada H, Katata G, Yamazawa H. Preliminary estimation of release amounts of ${ }^{131} \mathrm{I}$ and ${ }^{137} \mathrm{Cs}$ accidentally discharged from the Fukushima Daiichi nuclear power plant into the atmosphere. J Nucl Sci Tech. 2011;48:1129-34.

4. Tsuji M, Kanda H, Kakamu T, Kobayashi D, Miyake M, Hayakawa T, Mori Y, Okochi T, Hazama A, Fukushima T. An assessment of radiation doses at an educational institution $57.8 \mathrm{~km}$ away from the Fukushima Daiichi nuclear power plant 1 month after the nuclear accident. Environ Health Prev Med. 2011. doi: 10.1007/s12199-011-0229-7.

5. Ishikawa H. Evaluation of the effect of horizontal diffusion on the long-range atmospheric transport simulation in Chernobyl data. J Appl Meteorol. 1995;34:1653-65.

6. Koizumi A, Harada KH, Inoue K, Hitomi T, Yang HR, Moon CS, Wang P, Hung NN, Watanabe T, Shimbo S, Ikeda M. Past, present, and future of environmental specimen banks. Environ Health Prev Med. 2009;14:307-18.

7. International Commission on Radiological Protection (ICRP). Age-dependent doses to the members of the public from intake of radionuclides-part 5 compilation of ingestion and inhalation coefficients. ICRP Publication 72. Ann ICRP. 1995;26(1).

8. Department of Food Safety, Ministry of Health, Labour and Welfare. Handling of food contaminated by radioactivity (Relating to the accident at the Fukushima Nuclear Power Plant). March 17, 2011. http://www.mhlw.go.jp/stf/houdou/2r9852000001558e-img/2r9852 0000015apy.pdf and http://www.mhlw.go.jp/stf/houdou/2r9852000 001558e-img/2r98520000015av4.pdf 